\title{
Changes in Steam Pipeline Properties after Long-term Exposure
}

Jaroslava Svobodova, Libor Benes, Jaroslav Brabec

Faculty of Mechanical Engineering, J. E. Purkyne University in Usti nad Labem. Pasteurova 3334/7, 40001 Usti nad Labem. Czech Republic. E-mail: jaroslava.svobodova@ujep.cz, libor.benes@ujep.cz, j.brabec@schmenk.cz

The article deals with a practical problem solution of the steel 15128 steam pipeline properties change after prolonged exposure. Steam pipelines made of steel are stressed for a long time at higher temperatures and pressures and under conditions that are not constant throughout the pipeline operation. During operation, it occurs in the degradation processes, which are accompanied by changes in structure and mechanical properties. In terms of mechanical properties, it is mainly important the impact strength. The paper examines steam pipeline after long-term exploitation and results from microstructure evaluation, fractographic analysis, and comparison of impact strength test results.

Keywords: Steam pipeline properties, Mechanical properties, Microstructure, Impact resistance

\section{Introduction}

Steam pipeline steels are stressed for a long time at higher temperatures and elevated pressure. Their operating conditions are not constant due to various operating factors, for example, there are changes in temperature and pressure conditions during unavailability time. Long-term thermal exposure of these steels for steam pipelines, such as 15128 (K11591) steel, leads to degradation processes associated with structural changes and changes in mechanical properties. Structural changes are related to the reduction of free energy of the steel system [2]-[9]. During structural changes, the original ferritic-pearlite structure with lamellar pearlite and the presence of carbides inside ferritic grains changes. As a result of the reduction of the free energy, the lamellar cementite gains globulitic character and the carbide particles move to the ferritic grain boundaries, thereby occurs to the weakening the grain boundaries. In the consequence of the structural changes, there are the changes of mechanical properties. Extremely sensitive, in terms of mechanical properties, to structural changes, is the resistance of steel to failure characterized by impact resistance. The transit curve determined by this method shifts to the right towards higher temperatures relative to the initial (primary) state of the steel, thereby the steel can, in extreme cases, to get brittle already at room temperature. This can have catastrophic consequences when pressurizing the pipeline after an unavailability time. The contribution presents the results of structural and fractographic analyzes and impacts strength values of steam pipeline of steel 15128 after long-term exposure -186.728 hours.

\section{Experimental results and their discussion}

\subsection{Experimental material}

For experimental work was obtained a cut-out of steam pipeline about $1 \mathrm{~m}$ long after exploitation 186.728 hours at temperature of superheated steam $600{ }^{\circ} \mathrm{C}$ and pressure $10 \mathrm{MPa}$. Chemical analysis of the steel steam pipeline 15128 is given in Table 1.

Tab. 1 Element content [wt. \%]

\begin{tabular}{|c|c|c|c|c|}
\hline $\mathbf{C}$ & $\mathbf{M n}$ & $\mathbf{S i}$ & $\mathbf{C r}$ & $\mathbf{V}$ \\
\hline 0.14 & 0.58 & 0.25 & 0.64 & 0.31 \\
\hline
\end{tabular}

The chemical composition corresponds to the requirements of the material sheet ČSN 415128 for the given steel.

\subsection{Heat treatment}

To obtain the initial structure and the original properties of the steam pipeline, the following heat treatment was carried out for a part of the supplied steam pipeline cut-out: $980{ }^{\circ} \mathrm{C} / 6$ hours - air cooling +700 ${ }^{\circ} \mathrm{C} / 2$ hours.

Impact resistance tests at different temperatures were performed on U-notch samples taken from the steam pipeline in the longitudinal direction according to ČSN EN ISO 14556, results see Tables 2 and 3.

Transit curves for both states are shown in Figure 1. If we set the standard of $50 \mathrm{~J} \cdot \mathrm{cm}^{-2}$ as the criterion for the transition from tough to brittle state, then it can be stated that steel after 186.728 hours of exploitation is brittle up to temperature $40{ }^{\circ} \mathrm{C}$ and the steel does not comply with the specification of the cited standard for value KCU3 at temperature $20{ }^{\circ} \mathrm{C}$. On the other hand, the steel after heat treatment listed 
above, whose structure corresponds to the initial state, is still in a ductile state even at temperature $-20{ }^{\circ} \mathrm{C}$.

Tab. 2 Average KCU 3-A values from three measurements, after 186,728 hours

\begin{tabular}{|c|c|c|c|c|}
\hline $\mathbf{T}\left[{ }^{\circ} \mathbf{C}\right]$ & -20 & 0 & 20 & 40 \\
\hline KCU3 - A [J.cm-2 & 13.2 & 16.8 & 23.4 & 37.5 \\
\hline T [ ${ }^{\circ} \mathbf{C}$ ] & 60 & 80 & 100 & - \\
\hline KCU3 - A [J.cm-2 & 107.8 & 108.9 & 109.1 & - \\
\hline
\end{tabular}

Tab. 3 Average values of KCU 3-B from three measurements, the state after heat treatment

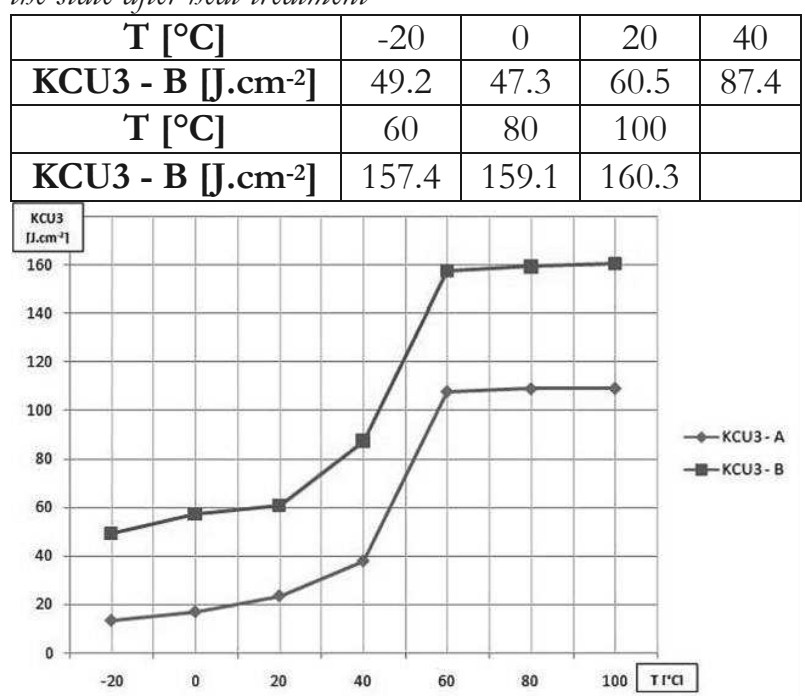

Fig. 1 Dependence of KCU3 on temperature

\section{Structural analysis}

Structural analysis was carried out both for steam pipeline after long-term exploitation and steam pipeline after heat treatment. An important finding was that there was no evidence of cavities in the steel structure after 186.728 hours indicating an advanced stage of degradation due to creep processes. The typical character of the ferrite-carbide structure of the steam pipeline after 186.728 hours of exploitation with eliminated carbide particles at grain boundaries is documented in Figure 2. The presence of lamellar perlite was detected.

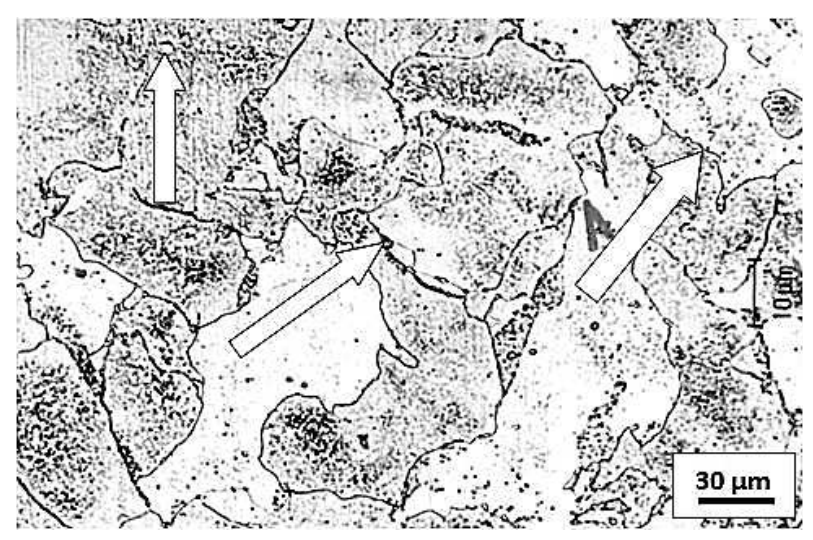

Fig. 2 Character of the 15128 steel structure after 186.728 hours of exposure at $600^{\circ} \mathrm{C}$ and $10 \mathrm{MPa}$ pressure

\section{Fractographic analysis}

The fractographic analysis was performed on the fracture surfaces of the bodies obtained after the impact toughness test at different temperatures. Documentation of fracture surface morphology of individual states is shown in Figures 3-5.

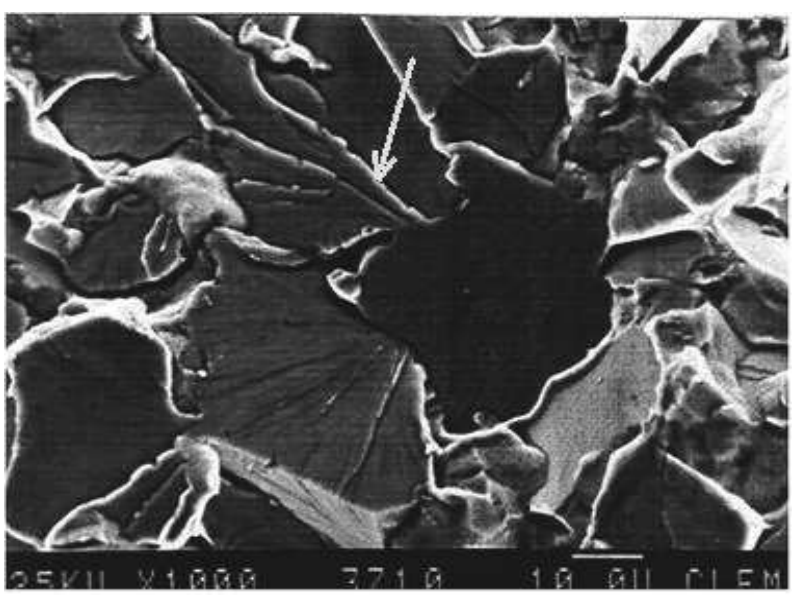

Fig. 3 Fragile area, river facets of the cleavage failure, sample A, KCU3 $=13.2 \mathrm{~J} . \mathrm{cm}-2, \mathrm{~T}=-20^{\circ} \mathrm{C}$

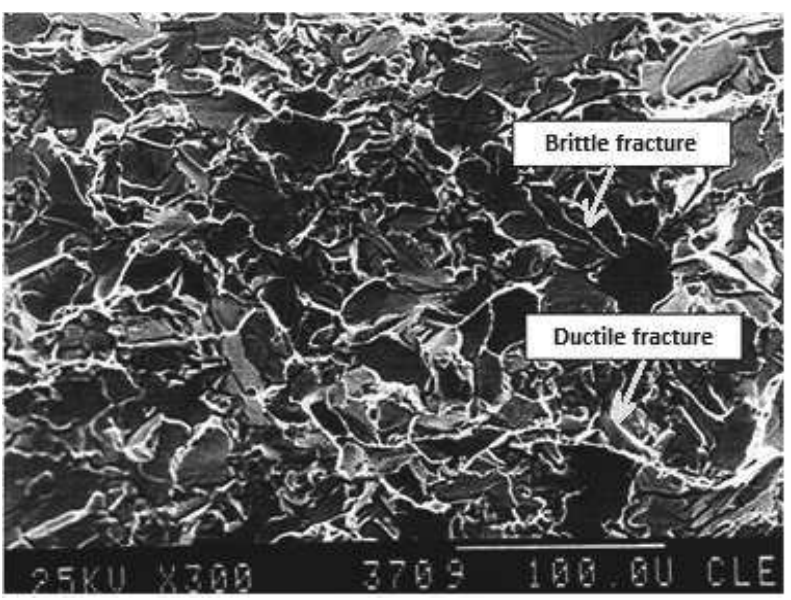

Fig. 4 Transit area, brittle and ductile failure, sample $A$, KCU3 $=37.5 \mathrm{~J} . \mathrm{cm}-2, \mathrm{~T}=40^{\circ} \mathrm{C}$

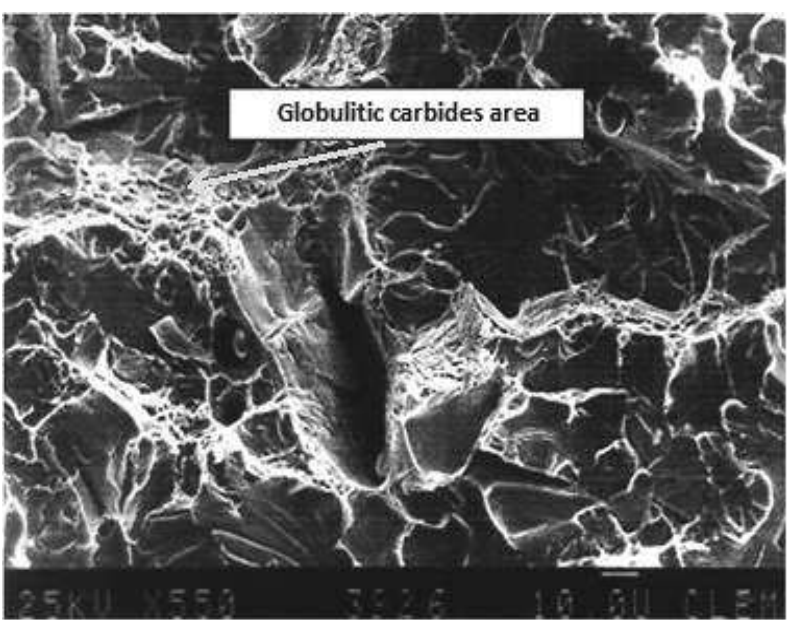

Fig. 5 Tough area, ductile failure, sample $A$, KCU3 =

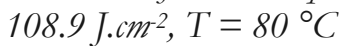


Figure 5 represents the fracture area of the ductile failure with the local region of the $\mathrm{Fe}_{3} \mathrm{C}$ globulitic carbides presence as a result of the changes in the surface tension of the original cementite lamellas in the pearlite grain.
Using statistical fractographic analysis was evaluated the percentage share of cleavage facets $\mathrm{F}$ in the fracture area of sample A. The values are shown in Table 4, graphical representation in Figure 6.

Tab. 4 Portion of the cleavage facets $F$ on the fracture area of samples after 186.728 hours of exposure

\begin{tabular}{|c|c|c|c|c|c|c|c|}
\hline $\mathbf{T}\left[{ }^{\circ} \mathbf{C}\right]$ & -20 & 0 & 20 & 40 & 60 & 80 & 100 \\
\hline $\mathbf{F}[\%]$ & 100 & 97 & 84 & 56 & 19 & 7 & 0 \\
\hline
\end{tabular}

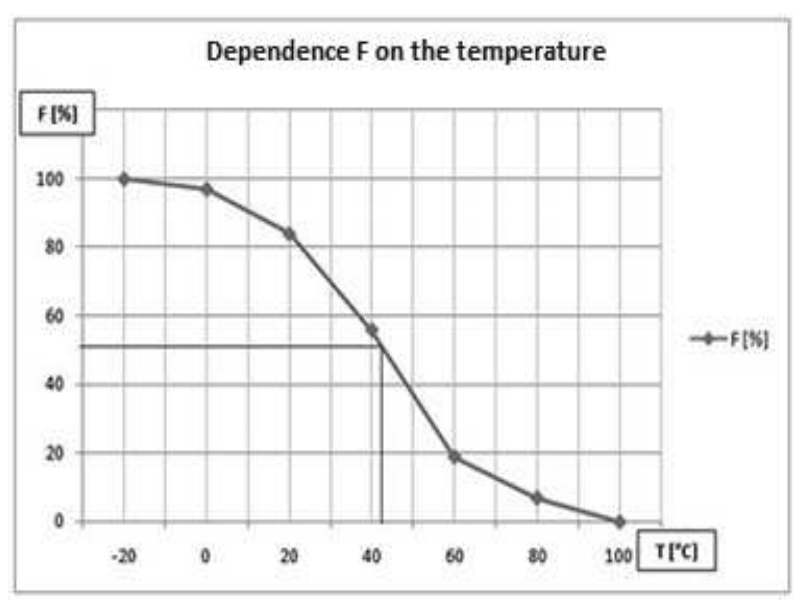

Fig. 6 Dependence of cleavage facets on the temperature

If the criterion for determining the transition temperature from brittle to the ductile state taking 50\% portion of cleavage facets on the fracture surface, then we can determine the transition temperature of this steel after given exposure to approx. $42{ }^{\circ} \mathrm{C}$. This temperature is in good agreement with the KCU3 criterion with a required value of $50 \mathrm{~J} . \mathrm{cm}^{-2}$, Figure 1, where the transit temperature was determined approx. $40^{\circ} \mathrm{C}$. The measured impact strength samples values of 15 128 steel after heat treatment are in good agreement with the published values for carbon steel with $0.2 \%$ $\mathrm{C}$ in the normalized state, Figure 7.

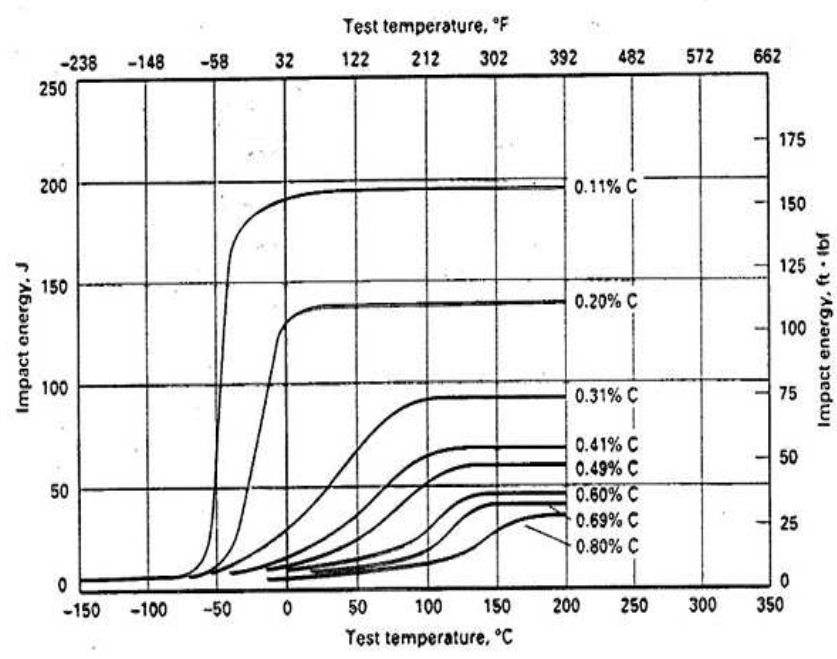

Fig. 7 Dependence of impact strength on temperature for carbon steels in normalized annealing state
Knowledge of dependence of structural changes and related mechanical values is very important in periodic material controls for individual systems of power equipment. Modern experimental instruments can realize the structural analysis "in situ" and interpret the acquired knowledge of mechanical properties and thus enable the assessment of the lifetime of the whole unit.

\section{Conclusion}

Based on the experimentally obtained results, we can pronounce the following main conclusions:

- The structural changes of the 15128 steel steam pipeline occurred after an exposure of the temperature $600^{\circ} \mathrm{C}$ and pressure $10 \mathrm{MPa}$.

- As a result of structural changes, the transit curve shifted to the right towards higher temperatures.

- Steel after the mentioned exploitation does not meet the requirement of the material sheet ČSN 415128 for the value of KCU 3 at room temperature.

- No structural changes related to creep processes were found in steel with the mentioned exploitation.

\section{References}

[1] Heat Treating (1991). ASM Handbook, Vol. 4, USA ASM.

[2] W. WAG-PING (2016). Fracture Failure Analysis of 4Cr13 Stainless Steel Linkages in Circuit Breakers. Case Studies in Engineering Failure Analysis, pp. 23-29.

[3] Fracture (2007). Suranaree University of Technology, May - August.

[4] D. K. MATLOCK (2014). Learning from the Past? Fatigue Failures in Engineering Systems. The Hatfield Memorial Lecture, Colorado School of Mines, Golden, Colorado, December.

[5] Failure Analysis of Engineering Materials (2002). Brooks C.R. et al, McGraw-Hill. 
[6] P. RAVINDRAN (2013). Fracture of Materials. Central University of Tamil, Nadu, India.

[7] S. MACKENZIE (2008). Overview of the Mechanism of Failure in Heat Treated Steel Components. ASM International.

[8] S. TURCOTT (2014). Metallurgical Analysis Included in the Inspection Toolbox. Steel Image Inc. Canada.

[9] S. P. LYNCH (2006). A Brief History of Fractography. Journal of Failure Analysis and Pretention, Vol. 6, pp. 54-69.

[10] J. BELAN, A. VAŠKO, L. KUCHARIKOVA, E. TILLOVA, M. MATVIJA (2018). The High-
Temperature Loading Influence on Orthorhombic Ni3Nb DOa $\delta$ - Phase Formation and its Effect on Fatigue Lifetime in Alloy 718. Manufacturing Technology, Vol. 18, No. 6, pp. 875882.

[11] Z. STUDENÝ, D. DOBROCKY, Z. POKORNY (2017). Importance of Diffusion Process on the Fatigue Life of Steel. Manufacturing Technology, Vol. 17, No. 1, pp. 94-99.

[12] P. PALČEK, M. ORAVCOVÁ, M. CHALUPOVÁ, M. UHRÍČIK (2016). The Usage of SEM for Fatigue Properties Evaluation of Austenitic Stainless Steel AISI 316L. Manufacturing Technology, Vol. 16, No. 5, pp. 1110-1115. 